\title{
Influence of personality on buying behaviour: a cross- cultural study comparing Poland and the UK
}

\author{
Paulina Wojciechowska \\ School of Arts and Social Sciences \\ City, University of London \\ Northampton Square, Clerkenwell, London EC1V OHB, Great Britain \\ paulina.wojciechowska@city.ac.uk \\ +48697887224
}

Received 21 August 2017/ Revised: 19 September 2017/ Accepted: 11 October 2017/ Published online: 25 October 2017

\begin{abstract}
The present study aimed to explore whether personality traits influence buying behaviour and if this influence differs depending on a different culture. The author focused on a crosscultural investigation of Poland and the UK. Data were collected via an online questionnaire which measured personality traits, consumer purchase behaviour and the meaning of branded products for 525 participants. The results show significant relationships between personality traits and both, consumer shopping styles and the way individuals perceived branded products. Personality traits were assessed by the MINI-IPIP test, a 20-items instrument which measures the Big Five personalities: Extraversion, Agreeableness, Conscientiousness, Neuroticism, and Intellect/Imagination (or Openness). Buying behaviour was tested by two scales. The first one was a 39-item Consumer Shopping Inventory (CSI), which indentifies eight shopping style dimensions: Perfectionist/High Quality Conscious, Brand Consciousness/Price Equals Quality, Novelty and Fashion Conscious, Recreational and Shopping Conscious, Price Conscious/Value for the Money, Impulsiveness/Careless, Confused by Overchoice, Habitual/Brand Loyal. Another instrument used was a 32-item the Meaning of Branded Products scale, presenting four dominant themes: Quality, Values, Personal Identity and Traditions. The present study also investigated the moderating effect of citizenship and other socio-demographic characteristics in the relation between personality traits and both, the meaning of branded products and shopping styles.
\end{abstract}

JEL classification: M5, D7

Keywords: Personality, buying behaviour, Poland, United Kingdom, CSI

\section{INTRODUCTION}

New markets are emerging in the global marketplace and existing markets are becoming increasingly fragmented as they split along subcultural and ethnic lines, therefore the managers of marketing campaigns are aware that they need to adapt to the new reality by running different marketing campaigns in different regions in an attempt to tailor their campaigns to meet the demands and preferences of different consumers (Melgoza, 2016). Strizhakova, Coulter and 
Price (2008) developed a scale that measures the meaning of branded products to different consumers. They examined previously conducted research in an attempt to relate the relative significance of branded products to various parameters such as: national traditions, group-identity, quality, family traditions, moral values, social status and self-identity. The results of this research provided us with information about how consumers in various countries relate to branded products (Gobé, 2001).

Moreover, market research indicates that consumers make purchasing decisions that are based on a diversity of decision-making processes: starting with the need/problem recognition, an information search, followed by the alternatives evaluation, purchase decision and finally postpurchase reflection (Mitchell et al., 1998). These processes in turn are based on a "consumer personality" which is an extension of the basic personality as it is described in the academic discipline of psychology. Sproles and Kendall (1986) found a way to reconcile the concept of personality in psychology with the consumer personality. Their Consumer Style Inventory (CSI) efficiently describes and matches the key characteristics of consumers with specific, unique shopping orientations for personal products. They classified eight different decision-making styles. (Sproles \& Kendall, 1986).

Although, there are some studies comparing the buying behaviour across countries, (BartosikPurgat, 2014; Visa UK, 2006), to the best of our knowledge there is a lack of significant research work investigating the cultural aspects of consumer behaviour and the way in which personality traits influence it, specifically between Poland and Britain. The present study will add to the literature in a significant way by investigating the extent to which personality traits may have a role to play in the conclusions that consumers' reach about various products and the way they purchase them and furthermore how these personality traits are affected by the prevailing consumer culture in two different economies. (Dąbrowska, 2008).

\section{LITERATURE REVIEW}

\subsection{Cross-cultural buying behaviour}

Culture is a shared experience that includes a wide variety of factors that influence the individual and shape society as a whole, these factors include: knowledge, beliefs, values, and customs. Human beings learn how to behave within their individual cultures; a great deal of this learning process takes place at the subconscious level. Cultures never remain the same, they change over time, but their central values are durable enough to be handed down from generation to generation, these values are not mere opinions, they are not due to the prevailing conditions, they are rather "an integral part of the consumer" (De Mooij, 2011). The Hofstede (1970) dimensional model of national culture is a very useful way to examine cross-cultural consumer behaviour. The five dimensions are as follows: Individualism/Collectivism, Power Distance, Masculinity/Femininity, Uncertainty Avoidance and Long/Short-Term Orientation.

The power distance (PD) dimension is defined as the degree to which less powerful members of a community accept the status quo of an unequal distribution of power. Polish society is notably hierarchical. This means that by and large, people accept their place in society and do not feel the need to demand any justification for the hierarchical order. (Boski, 2010). In contrast, British people generally believe that inequality should be kept to a minimum. In cultures that have a high power distance index, almost everyone knows their place in the social hierarchy and accepts their station in life. The concept of generally accepted societal hierarchies is important when it comes to understanding the influence of global brands. When the power distance index is high in a particular culture, one's social status must be obvious to others so that everyone knows who to respect (Hofstede, 2007). 
The contrast individualism/collectivism is defined as a measure of the tendency that people have to only look after themselves and their closest family versus a tendency to belong to an in-group that looks after them. With a score of 60, Poland is ranked as an Individualist society. Individuals within this framework are only expected to look after themselves and their closest families. However, Polish culture contains a "contradiction": Polish people may be highly individualistic, but they generally still need a hierarchy. This mixture of individualism and the need to find a well-defined place within the group structure creates a certain kind of "tension" within this culture, which needs to be managed carefully, but this contradiction may be resultful. Managers with Polish staff would be well advised to establish an unofficial line of communication which involves having personal contact with everyone in the structure, that way the impression is created that "everyone is important" in the company, although in reality, they remain unequal (Boski, 2010). The UK has an exceptionally high (89) score for individualism. The only generally accepted path to happiness is the achievement of personal fulfilment. People feel unique in individualistic cultures, they are "I"-conscious, so self-actualization is given a high priority. There is a widely held belief that their values are valid worldwide (Beck et al., 2015). Individualistic cultures rely on explicit verbal communication, facts are more important than the context. The sales process moves quickly because both parties want to conclude their business as soon as possible. On the other hand, in collectivistic cultures individuals are more sensitive to the needs of others; they are "we"-conscious. The style of communication in collectivistic cultures is indirect, it is vital to first grow a relationship based on mutual trust (Hofstede et al., 2007).

The masculinity/femininity dimension is defined as follows: The values which dominate a masculine society are success and achievement; while the values which dominate a feminine society are quality of life and nurturing. In masculine societies, achievement and performance are prioritized; and this achievement must be displayed, so high status products or brands that inspire envy such as expensive jewellery are relevant to show individual's success (De Mooij 2004). Poland achieves a score of 64 in this dimension therefore it may be described as a Masculine society. Generally speaking, people there "live with the purpose of working". (Boski, 2010). Britain scores 66, therefore it is also classified as a Masculine society - men are expected to be driven and highly success orientated. Compared to some Feminine cultures, the UK citizens live in order to work and generally have ambitions to achieve well defined goals. (Thompson, 2015)

Uncertainty avoidance is defined as the tendency that people have to feel threatened by ambiguity and uncertainty and the lengths that they will go to while trying to avoid these types of situations. People who live in cultures of strong uncertainty avoidance, feel a need for regulations and social formality in order to add a layer of structure to life. That people thirst for a sense of meaning and place their trust in experts. Additionally, more conservative people feel threatened by innovation and change. In contrast, people from low uncertainty avoidance cultures tend to be more active and express this attitude by playing more lively and adventurous sports. With a score of 93 on this dimension, Poles express a very high preference for avoiding uncertainty. Cultures that exhibit high Uncertainty Avoidance tend to have rigorous codes of belief and disapprove of unconventional ideas. These cultures have an emotional need for rules and regulations, time is money in such cultures and people are motivated by a need to feel secure (Boski, 2010). In contrast to Poland, the UK scores just 35 on the Uncertainty Avoidance scale which indicate that they are quite pleased to "muddle through" their days, they are not reluctant to change their plans when circumstances change. Being a low Uncertainty Avoidance Index country, the British are comfortable in situations of ambiguity, their recent decision to leave the European Union is a case in point. British people are generally not excessively fond of rules, but people are expected to strictly adhere to certain principles, e.g. the British fondness for queuing (Thompson, 2015).

Long/Short-Term Orientation is the extent to which population favours a pragmatic future oriented outlook rather than a short-term orientation based on the events of the past. The values induced by a long-term perspective are perseverance, maintaining a rigid social hierarchy, fiscal 
conservatism, and a strong sense of personal responsibility. A short-term orientation, tends to induce personal stability and steadiness through a strong sense of continuity and the chase of pleasure and happiness rather than the pursuit of contentment. Long-term orientated societies tend to invest in the future. In this dimension Poland achieved a low score of 38, this means that it is more traditional than pragmatic. They show a great respect for heritage and traditions, they do not tend to save for the future, and there is a focus on making small changes to achieve quick results. (Boski, 2010) Britain achieved a score of 51 in this dimension, this intermediate result means that a leading preference in British culture cannot be established.

Recent research were carried out in order to find a personality-trait model that can be adapted to collectivistic cultures. Application of the NEO-PI-R model among American and Chinese population, differences yielded a series of varied interesting results. (De Mooij, 2011). Cultures with a high score in Masculinity, which represents a focus on the ego and earning money also scored highly in Neuroticism, whereas Femininity is more related to an empathy with people and an interest in relationships. Cultures with strong Uncertainty Avoidance also achieved a high score in Neuroticism. A high extraversion level was found in individualistic cultures, which place a higher value on more independence, diversity and joy rather than on duty and strictness. Cultures with high Masculinity score and low Power Distance scores also achieved high scores in Openness to experience, which show that the culture values independent thought. Low Uncertainty Avoidance also correlated with Agreeableness, which can be found in cultures with High Tolerance. Conscientiousness also correlated well with a high Power Distance score. Different values and attitudes lead to a specific way of shopping (e.g. smart shopping) and the culture that we live in forms those values and attitudes, therefore culture can be used to explain consumer behaviour (Hofstede, 2011).

\subsection{Consumer decision making styles- Consumer Styles Inventory (CSI)}

Numerous studies have been conducted in order to distinguish consumer profiles since the 1950's (Kozhevnikov, 2007; Riding et al., 1991). These studies have produced a variety of opinions with regard to the main factor that influences the way in which we make decisions. Marketers are concentrating on attempting to identify the external factors which might lead consumers to decide to shop. Psychologists take a different approach, they are more concerned on the internal factors which influence consumer behaviour, so they concentrate on trying to unlock the secrets of the personality.

Sproles and Kendall's (1986) CSI efficiently describes and matches the key characteristics of consumers with specific, unique shopping orientations for personal products. This research team believes that consumer decision-making patterns are, in effect, mental orientations that characterize the manner in which consumers approach the process of making purchasing decisions. They found a way to reconcile the concept of personality in psychology with the consumer personality, the results of their work have been relatively effective in explaining the ways in which consumers make decisions in different situations. They classified eight different mechanisms of decision-making, which are categorized as follows:

\section{Brand conscious consumer}

Brand conscious consumers prefer bestselling brands with higher prices, for them the more high-priced and well-known brands guarantee quality. According to Fernandez (2009) Generation Y (people born during 1980s and early 1990s) uses branded clothes as a way to tell the world that they belong to a particular group, or at least that they aspire to belong to it. In this context, branded clothes are displayed rather than just worn, it is used to project a positive image, it is a badge of success. Aaker (1997) has taken the novel approach of giving brands a human personality in order to define them, brands can be divided into five brand personalities, each personality has 
a range of human characteristics that are linked to it. The five brand personalities are as follows: competence (assertive, smart, calm - this is related to Conscientiousness), sincerity (authentic, straightforward, honest - this is related to Agreeableness), sophistication (attractive, seductive, this is related to affluence and status), excitement (adventurous, exciting, modern - this is related to Extraversion) and ruggedness (enduring, masculine). Brand choice is driven by the powerful personality of the brand (Guthrie et al., 2008).

\section{Novelty-fashion conscious consumer}

These consumers want to keep up to date with the latest trends, this aspect of consumerism is of paramount importance to them. They seek variety and derive a sense of pleasure when they find a new style. (Chang et al., 2004) Fashion-conscious shoppers have been used in a variety of studies to predict the shopping patterns of others with regard to adopting newest styles of fashion. One particular new style of fashion called eco-friendly was investigated by Gam (2011). This study indicated that individuals who are up-to-date with newest fashion read a lot of fashion papers on a regular basis, at the time the magazines were discussing the advantages and benefits of eco-friendly clothing, therefore the readers of these magazines tended to try out new fashion items sooner than other consumers. They were more eager to accept eco-friendly fashion as a new style.

\section{High-quality conscious consumer, perfectionist}

This consumer class search for the best quality in every product category. They shop carefully and compare products in order to gain the one that suits them perfectly, they are systematic rather than impulsive. Their quality ratings criteria of products differ. The quality of the product is usually the deciding factor that influences the formation of an opinion about the company, this is particularly the case when the consumer is unfamiliar with the brand. Fiore and Damhorst (2006) distinguished product attributes according to the way in which shoppers perceive quality, there are two distinct groups: intrinsic (inherent) and extrinsic (external). The intrinsic attributes of products are related to the nature of the product and therefore they cannot be modified without changing the product itself. The most obvious intrinsic attribute of a product is its physical appearance. The extrinsic attributes of products involve the ways in which the product is perceived due to external factors such as the brand name and the level of advertising. Consumers who usually depend more on the extrinsic attributes of products while shopping are usually less experienced with the products than shoppers who are aware of their intrinsic attributes and therefore pay less attention to marketing campaigns.

\section{“Value for money"- price conscious consumer}

Consumers in this category are always trying to find value for their money and they often prefer to pay sales prices. The study of Ram (2009) has indicated that individuals who tolerate higher prices are usually more utilitarian than recreational consumers. They pay a higher price for the sake of comfort and time saving, they often confine themselves to shopping in one store. In contrast, recreational shoppers enjoy taking the time to hunt for a good buy.

\section{Recreational and shopping conscious consumer}

Consumers in this category don not take shopping seriously, they usually shop purely as a recreational activity. Numerous studies have come to the conclusion that these consumers find that the act of shopping gives them a sense of pleasure whether or not a purchase is made. These consumers derive a special pleasure from shopping for clothes. Hirschman et al. (1982) defined hedonic consumption as a type of buying behaviour that derives from fantasy, there are 
emotive aspects associated with certain products, this indicates that shoppers in this category are motivated by amusement. Chang et. al. (2004) suggest that hedonic goods involve the consumer at an emotional level and that variety-seeking behaviour produces hedonic shopping. Different types of product have different hedonic values. Fashion products which can have an almost infinite variety, have a much higher hedonic value than utilitarian products such as cleaning supplies. It was also found that men tend to derive shopping satisfaction from the interior of the store rather than from the products themselves. By contrast, women derive a sense of satisfaction when their perceived needs are met, this may occur when kind and helpful personnel offer them a high level of service.

\section{Confused by over-choice consumer}

Consumers may feel tiredness due to the number of products on offer, the number of different brands and places from which they can be purchased, this may be overwhelming for some consumers and experienced as a sort of "information overload" which causes confusion. For this reason consumers in this category often have problems deciding so they choose the very first product or service that meets their minimal requirements to save time rather than considering the alternatives.

\section{Impulsive, careless consumer}

These consumers do not believe in planning ahead and sticking to a budget. The behaviour of impulse buying is a result of the impact of marketing-mix strategy and the personal attributes and traits of the consumer (Gąsiorowska, 2011). With regard to the five personality traits of consumers discussed above; Neuroticism is positively correlated with a risk-aversive behaviour because it is linked to the feeling of anxiety, while Openness to Experience positively predicts impulsive behaviour (Dowd \& McElroy, 2007). A study conducted by Wang and Zhang (2010), revealed a relationship between impulsive, careless buying and cognitive dissonance. Careless and impulsive consumers generally encounter less cognitive dissonance than consumers who carefully schedule their shopping trips. Very often impulsive shoppers are driven not by a logic but emotions that may change while they are shopping and affect their purchasing behaviour.

\section{Habitual, brand-loyal consumer}

As the name suggests these shoppers are usually loyal to particular favourite brands and stores. Bloemer's \& Kasper's (1995) study has indicated that brand loyalty and repeated purchases are not the same thing, because the latter does not necessarily include any serious degree of commitment. Brand loyalty may be subdivided into spurious and true brand loyalty, where true brand loyalty is a product of psychological processes in which commitment is involved. Whereas, spurious loyalty is merely the result of such an unconscious bond, it is not built on any real devotion to the product or brand. The truly loyal buyer will typically purchase the same brand repeatedly due to the strong dedication that he has to the brand. In contrast, the spuriously loyal consumer may only choose to purchase the same brand over and over again because he perceives this activity as a way to save time and avoid the risk involved in making an unknown choice.

\subsection{Consumer decision making and personality}

The Big Five model is a widely used approach to the study of personality traits. The model has allured the interest of numerous researchers from many disciplines like sociology, management or marketing due to its capacity to help to explain seemingly irrational human behaviour. Personality is the reflection of subtle individual differences between people. It is a powerful concept because it allows us to categorize buyers into various groups based on one or more personality traits. 
Almost everyone shares their personality traits, the combinations of personality traits are unique to the individual rather than the traits themselves, otherwise it would be impossible to classified consumers into different categories. Unlike other aspects of behaviour, personality is usually enduring and consistent. Even though marketers cannot alter the personalities of consumers to persuade them to buy their products, if they are aware of which personality-characteristics have an impact on specific consumer reactions and responses, then they can make an informed attempt to play on that essential traits deep-rooted in a chosen group of consumers to influence their decisions.

The literature of the "Big Five" factor model refers to five factors in the human personality which consists of the following traits: neuroticism, extraversion, openness, conscientiousness and agreeableness. Openness is associated with a deep interest in novelty, style, and new ideas (McCrae and Costa, 1997) Extraversion indicates a sociability, confidence in the future and ambition. Agreeableness exhibits an individual's humanity, benevolence, and willingness to cooperate in social interactions. Conscientiousness characterises a person who is dependable, trustworthy, determined and industrious (Martins, 2002). Neuroticism is a negative state, it is linked to emotional instability which can lead to high level of anxiety and stress (Migliore, 2011). People are complicated so depending on time and situation, they can reflect all five dimensions to a certain degree, but they may score higher on one dimension and lower on several others (McCrae and Costa, 1990).

The Big Five Personality traits may be explained further by using real cases involving the analysis of consumer behaviour, the Extraversion means that the client is naturally outgoing, typically this kind of consumer likes to impress others (Lynn, 2008). They are more confident than other consumers with different personality traits. They are also more sensitive to their environment, this is obvious because all of their emotions are openly expressed. Agreeableness, this personality includes a category of buyers who is easier to do business with. They are not so self-centred and easily accept the opinions or suggestions of other people. Conscientiousness, these consumers are careful, they are also much more likely take responsibility than other consumers. This type of personality is naturally assiduous and careful. In contrast to the sensitivity of the extraversion client, this is a category of consumers who possess emotional stability. Emotionally stable people think more rationally, they are adept at remaining in control in unfamiliar situations.

Due to the fact that personality is such a complex area, there is no consistency among researchers' studies on the association between personality and purchase buying behaviour. Various studies have found a relationship between product use and personality (Cleff et. al, 2013; Aaker 1997), while others have not (Blackwell et. al, 2007; Crossby and Grossbart, 1984;). Even though the researchers have different opinions, there is some common ground, in most studies, for example, researchers have revealed that personality have a powerful influence over our intentions. (Hawkins et. al, 1995). For instance, it has been noted that buyer personality forms an important part of the influences which act on the consumer as they evaluate different brands. What is more, Mulyanegara et. al (2009) in their research studies have found a compelling correlation between consumer behaviour and personality traits. They discovered that: "shoppers who reflects a conscientious personality show a tendency to be attracted to 'Trusted' brands. On the other hand, extroverted consumers feel motivated by brands that they regard as "sociable". The literature also indicates that the neuroticism trait has a definite negative effect on decision making while the extraversion trait has a definite positive effect (Costa \& McCrae, 1980). For example, consumers experiencing high levels of neuroticism may need assistance to manage their levels of stress because consumers with high levels of neuroticism have a tendency to be nervous, tense, depressed and guilty and they also tend to have low self-esteem (McCrae \& John, 1992), these conditions clearly occur both before and after they make a purchase, perhaps surprisingly, even people with a relatively high level of education may suffer from this personality trait. 
On the other hand, consumers with a low level of consciousness along with a low level of education may have an issue with concentration and may have trouble positively interacting with others throughout the purchasing process. Moreover, various studies revealed that certain dimensions of the Big Five personality model (Conscientiousness, agreeableness and openness) show a positive correlation to knowledge-sharing intentions during the purchasing processes and web usage (eg. product information searches) (Cabrera, 2006).

Although, as we can see, there is a wealth of literature exploring the ways in which consumers make decisions, there are, as yet, no studies that compare the role that personality plays in consumer behaviour among the citizens of Poland and Britain.

\subsection{Meaning of branded products}

The importance of branded products has been well documented over the last decade both by scholars (Aaker et. al., 2004; Holt et. al., 2004) and by people involved in the retail trade (Gobé, 2001). The majority of the discussion related to brands has been focused on particular brands such as Marlboro or Nike. Several authors (Coulter et. al., 2003), however, have examined the more widespread concept of the relationship that consumers have with branded products. Firms expand brands to make their products stand out, and brands also serve the needs of consumers. Branded products, in general, can be defined as "aggregate of consumers' perceptions, insights and feelings about the product's features and attributes and how it performs in real life, about the name of the brand and what it means to the consumer, and about the company related to that brand" (Keller, 2003).

Strizhakova, Coulter and Price have developed a way to measure the meanings of branded products with a scale. Their attentive and coherent analysis of existing literature disclosed seven important meanings: quality as defined by an association with risk reduction (Tsai, 2005), as well as brands that serve as intentional signals of social status (Coulter et al., 2003), as a reflection of the personality (Aaker, 1997), as a mechanism for group formation through an association with other brand lovers (Bagozzi et al., 2001), as associated with personal values and beliefs (Gelb \& Sorescu, 2000), as connected to both family traditions (Fournier, 1998) and national/ ethnic heritage (Kaynak \& Kara, 1998). Their investigation also revealed that the seven observed meanings can be summarized by just four meanings:

1. quality

2. personal identity (including self-identity, group identity, and social status)

3. values

4. traditions (including family traditions and national traditions)

Being a powerful signal to consumers, the quality and reliability of branded products have been one of the crucial selling features among many companies. From the sellers' perspective, many firms have built successful and prosperous brands based on an association with quality (Hellofs and Jacobson, 1999). What is more, in the rapidly changing countries of India or Central Europe, quality is a powerful sign; individuals often favour foreign (usually Western) brands because these brands are considered as being of higher quality (Feick et. al., 1995).

For companies, a principal feature of brands is also their capability to differentiate the product from among alternatively comparatively homogeneous goods; briefly, brands try to create unique and specific identities for a company's products in its consumers eyes (Keller, 2003). What is more, Levy's theory suggesting that branded products are symbols of the self, has started the discussion among many researchers about the ways in which individuals incorporate and use the meanings related with their branded products to communicate various characteristics of their identity (Escalas and Bettman, 2005; Levy, 1959). Moreover, due to the fact that firms can produce an association with other owners or users of a certain brand, branded products are 
also a root of group-identity (O'Guinn \& Muniz, 2001). Branded products also have meanings that convey status, firms associate their products and brands to positions of higher social status. Hence, individuals buy high-status brands to boost and display the social class they belong to. Additionally, numerous studies reveal that consumers in developing regions/countries prefer foreign, most often, Western brands for the simple reason that these brands work as status symbols (Coulter et al., 2003).

Moreover, many global and multicultural companies consciously attempt to relate their products and brands to the values, beliefs and interests of their consumers. Avon is an excellent case, with their campaigns dedicated to many women's matters, including the Avon Foundation Breast Cancer Crusade. In fact, as well as philanthropy associated with the companies and their noble values linked to the products and image, give them a powerful competitive asset and advantage. These firms believe that charity work is no longer just a preference or a choice, but a condition to arise in the modern marketplace and increase the brand loyalty among consumers (Barbaro, 2006).

Furthermore, since many studies have documented the fact that particular brands can mirror a family traditions and memories, (Moore et al., 2002), many firms have started to advertise brands as the reflection of the family ties and tradition among the consumers to gain a strong and genuine attachment to the brand. Companies and buyers also relate brands to ethnic and national traditions (Penaloza, 1994). Research has revealed the power of ethnic identification by investigating the main reason of using the Spanish-speaking channels and buying national brands among Hispanic-Americans. (Deshpande et al., 1986).

The application of the scale discussed above should provide global marketing managers with an indication of how individuals in certain countries project meaning onto branded products and this information should be used to consistently adapt communication and marketing strategies accordingly.

\section{DATA AND METHODS}

\subsection{Research question}

The current cross-cultural study aimed to investigate the influence of consumers' personality on shopping styles and how they perceived branded products. It is believed that this study may help to customize certain products and marketing campaigns taking into account people's personality and how it differs among countries. The key research hypotheses, therefore, include:

H1: Poland scores higher on neuroticism than United Kingdom

H2: Imagination/Intellect scores higher among British citizens

H3: Extraversion scores higher among British citizens

H4: Relationship between Polish and British citizens is different concerning the influence of personality on the shopping styles

H5: Age, gender, education and income of consumers play a moderating role for the effect of personality traits on decision making styles among Polish and British citizens

H6: Personality has an impact on our shopping styles

H7. Relationship between Polish and British is different concerning the influence of personality on the meaning of branded products

H8. Age, gender, education and income of consumers play a moderating role for the effect of personality traits on the meaning of branded products among Polish and British citizens

H9: Personality has an impact on the meaning of branded products 


\subsection{Sample and procedure}

Participants were recruited online via Prolificacademic.com (Prolific) and social networking sites (Facebook) over a 2-month period from July to September 2016. To access the study, participants had to click on a link which sent them directly to a secure online survey on the Qualtrics platform. An information sheet and debrief were included at the beginning and the end of the questionnaire. Respondents had to complete a questionnaire which measured their personality, consumer decision-making styles and the meaning of branded products, among other variables. Respondents who were recruited through Prolific were provided with a certain incentive to encourage them to take part in the survey ( $£ 1$ per person). For the purpose of the research, participants who were citizens of the UK and Poland and over the age of 18 were the only ones included in the sample. All other nationalities were excluded from the research. Furthermore, taking into account that respondents were recruited from two different countries and thus, different languages and cultures, the questionnaire was adapted for both: English and Polish speaking participants. The translation had three stages:

1. Translation from English to Polish, retaining the semantic meaning of the items, not the literal meaning which sometimes might be confusing.

2. Back translation by a different person, from Polish to English, also retaining the semantic content.

3. Verification of the back translation by an expert proficient in English to confirm that the questionnaire is essentially the same as the original.

The final sample $(N=525)$ consisted of 264 British and 261 Polish citizens. The present study have gathered 156 females and 108 males among British citizens between the ages of 18 and 74, with a mean age of $34.6(\mathrm{SD}=12.06)$ and 204 females and 56 males among Polish citizens between the ages of 18 and 64 , with a mean age of $26.6(\mathrm{SD}=8.14)$

\subsection{Measures}

\subsubsection{Consumer decision-making styles}

The Consumer Styles Inventory (CSI) was used to assess consumer decision making styles, our dependent variable. An instrument developed by Sproles and Sproles (1990) is composed of thirty-nine items that cover the eight consumer shopping styles mentioned above. Thirty-one of the items were positively worded and eight were negatively worded. All items are scored on 5-point Likert-type scales ranging from strongly disagree (1) to strongly agree (5). Item scores are summed within each style separately to create combined scores for each style (Table 1).

\subsubsection{The meaning of branded products}

The meaning of branded products was assessed with a 32-item measure developed by Strizhakova, Coulter, and Price 2008. The scale is created of six first-order dimensions (selfidentity, group-identity, status, quality, values and traditions). Self-identity, group identity and status are measured by five statements each and are grouped into the second-order dimension labelled as "Personal identity". Quality is measured by five and Values by three items. Traditions covers facets of family traditions (five items) and national traditions (four items). Each statement is valuated on a 7-point Likert scale. Respondents were asked to indicate their responses on a 7-point scale ranging from (1) strongly disagree to (7) strongly agree. Item scores within a dimension and can be summed and averaged to form a dimension mean score (Table 1). 


\subsubsection{Personality traits}

The MNI-IPIP test was used (Donnellan et al., 2006) to measure personality among Polish and British citizens. This 20-items instrument measures the Big Five personalities: Extraversion, Agreeableness, Conscientiousness, Neuroticism, and Intellect/Imagination (or Openness). Respondents were asked to describe how accurately each statement describe them on a 5-point scale ranging from (1) very inaccurate to (5) very accurate. High scores point out that the individual has many traits which are similar to the traits measured by the subscale while low scores signify that the person does not have many traits which correspond to the traits measured by the subscale. Descriptive statistics for these scales are combined and presented in Table 1.

Table 1

Cronbach's Alpha Reliability and Descriptives of Study Variables

\begin{tabular}{|c|c|c|c|c|c|c|c|c|}
\hline & $\mathbf{N}$ & M & Me & SD & Q & Min & Max & alpha \\
\hline \multicolumn{9}{|l|}{ Personality traits } \\
\hline Extraversion & 481 & 12.72 & 13 & 4.229 & 3.5 & 4 & 20 & 0.87 \\
\hline Agreeableness & 481 & 15.69 & 16 & 3.072 & 2 & 4 & 20 & 0.78 \\
\hline Conscientiousness & 481 & 13.62 & 14 & 3.519 & 2.5 & 4 & 20 & 0.75 \\
\hline Neuroticism & 481 & 12.62 & 13 & 3.388 & 2.5 & 4 & 20 & 0.71 \\
\hline Imagination/ Intellect & 481 & 15.09 & 16 & 3.032 & 2 & 4 & 20 & 0.71 \\
\hline \multicolumn{9}{|l|}{ Shopping styles } \\
\hline High Quality Conscious & 463 & 26.56 & 27 & 4.660 & 3 & 11 & 35 & 0.86 \\
\hline Brand Consciousness & 463 & 15.77 & 16 & 4.350 & 3 & 6 & 29 & 0.81 \\
\hline Novelty and Fashion Conscious & 463 & 15.41 & 15 & 3.729 & 2.5 & 6 & 25 & 0.75 \\
\hline Recreational Conscious & 463 & 15.21 & 15 & 4.416 & 3.25 & 5 & 25 & 0.84 \\
\hline Price Conscious & 463 & 9.45 & 9 & 2.209 & 1.5 & 3 & 15 & 0.55 \\
\hline Impulsiveness/Careless & 463 & 13.55 & 13 & 3.770 & 2.5 & 5 & 24 & 0.74 \\
\hline Confused by Overchoice & 463 & 11.43 & 11 & 3.372 & 2.5 & 4 & 20 & 0.81 \\
\hline Habitual/Brand Loyal & 463 & 14.02 & 14 & 2.561 & 1.5 & 4 & 20 & 0.68 \\
\hline \multicolumn{9}{|l|}{ Brand meanings } \\
\hline Quality & 443 & 22.02 & 23 & 6.006 & 3.5 & 5 & 35 & 0.90 \\
\hline Values & 443 & 11.47 & 12 & 4.171 & 3 & 3 & 21 & 0.88 \\
\hline Self indentity & 443 & 18.16 & 19 & 7.306 & 6 & 5 & 35 & 0.94 \\
\hline Group identity & 443 & 15.15 & 15 & 7.237 & 5 & 5 & 35 & 0.93 \\
\hline Status & 443 & 13.88 & 12 & 7.379 & 6 & 5 & 35 & 0.94 \\
\hline Family Traditions & 443 & 15.58 & 15 & 7.380 & 5.5 & 5 & 35 & 0.93 \\
\hline National Traditions & 443 & 11.20 & 11 & 5.422 & 4 & 4 & 27 & 0.91 \\
\hline Personal identity $(\mathrm{SI}+\mathrm{GI}+\mathrm{S})$ & 443 & 47.19 & 46 & 19.236 & 14.25 & 15 & 102 & 0.95 \\
\hline Traditions $(\mathrm{FT}+\mathrm{NT})$ & 443 & 26.78 & 26 & 11.559 & 9 & 9 & 59 & 0.93 \\
\hline
\end{tabular}




\subsubsection{Control variables}

Previous researches have revealed that education, gender and age are a key indicators of consumer decision making style and may influence buyers' shopping behaviour. (Fast et al., 2005). Due to that information, the present study included those variables in a model to confirm or reject that relationship with our dependent variables. Additionally, respondents were asked about their income to find out if there is any correlation between these variables and buying behaviour among the participants.

\subsection{Analytical Methods}

The present study included three tests: MINI IPIP, CSI and The meaning of branded products scales, for which the value of Cronbach's alpha ranged from: $0.71-0.87,0.55-0.86$, 0.88-0.95. All scales were created by summing the responses (some questions were reversed). All hypotheses concerning the relationship between two scales (H6,H9) were verified by testing the significance of the Pearson's correlation. The relationship between the personality or shopping styles and the citizenship (H4,H7) was verified by using the t-test for independent samples. It was used to compare the means and analyze if they are significantly different from each other. based on independent data. T-test, as a parametric analysis, assumes that the sampling means are normally distributed and the variances are equal. (Field, 2012) First it was needed to check if the assumptions that underlies the t-test were true. To do that the Levene's test for homogeneity of variances had to be done. To avoid problems with the violation of assumption we used the Welch's t-test for independent variables. Hypotheses with moderators $(\mathrm{H} 5, \mathrm{H} 8)$ were tested by using regression analysis, examining the significance of the interaction.

\section{RESEARCH RESULTS}

\section{Personality traits and citizenship}

Firstly, three independent t-tests were run to check if personality traits differ between Poland and the UK and if were differences are significant. It was found that Poland scored higher on Neuroticism $(\mathrm{M}=13.44, \mathrm{SD}=2.93)$ than British citizens $(\mathrm{M}=11.84, \mathrm{SD}=3.61)$, $\mathrm{t}=5.35 ; \mathrm{p}<0.001$, so $\mathrm{H} 1$ is supported. Although contrary to the second hypothesis $(\mathrm{H} 2)$, the difference between Poland $(\mathrm{M}=15.12, \mathrm{SD}=3.03)$ and the $\mathrm{UK}(\mathrm{M}=15.07, \mathrm{SD}=3.04)$ concerning Imagination/Intellect (or Openness) was not significant, $t=0.195 ; p=0.85$. T-test also revealed, contrary to the hypothesis, $(\mathrm{H} 3)$ that Extraversion scored higher among Polish citizens $(\mathrm{M}=14.26, \mathrm{SD}=3.83)$ than Britons $(\mathrm{M}=11.24, \mathrm{SD}=4.07), \mathrm{t}=8.39 ; \mathrm{p}<0.001$.

\section{Personality and shopping styles}

Secondly, regression analysis was conducted to test the moderating effect of citizenship in the relation between shopping styles and personality traits among Poland and the UK. It could reveal if relationship between Polish and British citizens is different concerning the influence of personality on the shopping styles (H4). It was found that a citizenship is a moderator in the relation between the Recreational and Shopping Conscious style and Extraversion trait $(p<0.01)$. Among Poles there is no significant relationship between these variables $(r=0.10 ; p=0.15)$, whereas around the UK this relation is significantly positive $(r=0.36 ; \mathrm{p}<0.001)$. 
Table 2

The results of Regression Analysis to Test Moderating Role of Citizenship for the Effect of Personality traits on Consumer Shopping Styles

\begin{tabular}{|c|c|c|c|c|}
\hline & beta & SE & $\mathrm{T}$ & $\mathbf{p}$ \\
\hline (Intercept) & 0.04 & 0.07 & 0.562 & 0.574 \\
\hline IPIP_E & 0.1 & 0.07 & 1.371 & 0.171 \\
\hline CitizenshipUK & 0.03 & 0.1 & 0.365 & 0.715 \\
\hline IPIP_E:CitizenshipUK & 0.3 & 0.1 & 3.126 & 0.002 \\
\hline
\end{tabular}

Additionally, another regression analysis was conducted to test the moderating effect of age, gender, education and income on consumers' behaviour in both countries. The main reason was to check if these variables play a moderating role for the effect of personality traits on decision making styles among Polish and British citizens. (H5) Results presented in Table 3 and 4 suggested that gender moderated the effect of Imagination/Intellect on the Habitual Brand-loyal conscious shopping style $(\mathrm{p}<0.01)$. Among females there is no significant Relationship between these variables $(r=-0.01 ; p=0.86)$, whereas among males this relationship is significantly negative $(\mathrm{r}=-0.27 ; \mathrm{p}<0.01)$.

Table 3

Regression Analyses to Test Moderating Role of Socio-demographic characteristics for the Effect of Personality traits on Consumer Shopping Styles

\begin{tabular}{l|c|c|cc} 
& Beta & SE & T & P \\
(Intercept) & 0.05 & 0.07 & 0.750 & 0.454 \\
IPIP_Imagination/Intellect & 0.00 & 0.06 & 0.051 & 0.959 \\
GenderMale & -0.22 & 0.12 & -1.853 & 0.065 \\
Age & -0.22 & 0.06 & -3.764 & $<0.001$ \\
Education & 0.02 & 0.06 & 0.424 & 0.672 \\
Salary & 0.21 & 0.06 & 3.608 & $<0.001$ \\
IPIP_Intellect/Imagination:GenderMale & -0.31 & 0.11 & -2.925 & 0.004
\end{tabular}

Table 4

The results of the Regression Analysis for variables: Imagination/Intellect and Gender

\begin{tabular}{l|c|c|c|c} 
& Beta & SE & t & p \\
(Intercept) & 0.05 & 0.06 & 0.887 & 0.376 \\
IPIP_I & -0.01 & 0.06 & -0.175 & 0.861 \\
GenderMale & -0.17 & 0.10 & -1.715 & 0.087 \\
IPIP_I:GenderMale & -0.28 & 0.10 & -2.831 & 0.005
\end{tabular}

Additionally, Pearson correlations were computed to investigate the relationship between personality traits and the shopping styles (H6). Pearson correlations revealed a significant positive correlations between Conscientiousness and the Careful quality-conscious shopping style $(\mathrm{r}=0.13 ; \mathrm{p}<0.01$, Table 5$)$ and significantly negative correlation between Conscientiousness and the Impulsively careless shopping style. What is more, there was no significant correlation between Conscientiousness and Price-conscious shopping style $(r=-0.01 ; p=0.82$, Table 5). 
Conducted study also revealed a significantly positive correlation between Extraversion and Brand- conscious shopping style $(\mathrm{r}=0.16 ; \mathrm{p}<0.001$, Table 5) and negative correlation between this personality trait and price-conscious shopping style $(r=-0.32 ; \mathrm{p}<0.001$, Table 5). Additionally, Extraversion is positively correlated to the Impulsiveness-Careless shopping style $(\mathrm{r}=0.25 ; \mathrm{p}<0.001)$.

Moreover, a significant positive correlation between Imagination/Intellect and Novelty/ Fashion- conscious shopping style was also found $(r=0.09, \mathrm{p}<0.05$, Table 5$)$. The same personality trait is also negatively correlated to the Habitual brand-loyal shopping style $(r=-0.10$; $\mathrm{p}<0.05$, Table 5).

Contrary to the hypothesis, Pearson correlations revealed a significant positive correlations between Neuroticism and the Impulsiveness/Careless-conscious shopping style $(r=0.19$; $\mathrm{p}<0.001$, Table 5). Additionally, the present study also found a significantly positive correlation between Neuroticism and the Confused by over-choice shopping style $(r=0.10 ; p<0.05$, Table 5).

Contrary to the prediction, Pearson correlation did not find any evidence of a significant association between Agreeableness and the Habitual brand-loyal shopping style $(\mathrm{r}=0.00$; $\mathrm{p}=0.98$ ) however, there was a significant positive relationship between Agreeableness and the Recreational shopping style $(\mathrm{r}=0.21, p<.001$, Table 5)

Table 5

Correlation between Personality traits and Consumer Shopping Styles among Polish and British citizens

\begin{tabular}{|c|c|c|c|c|c|}
\hline & IPIP_E & IPIP_A & IPIP_C & IPIP_N & IPIP_I \\
\hline High Quality & $0.10^{*}$ & $0.14^{* *}$ & $0.13^{* *}$ & -0.05 & $0.17^{* * *}$ \\
\hline Brand conscious & $0.17^{* * *}$ & -0.05 & -0.01 & -0.02 & $-0.16^{* * *}$ \\
\hline Novelty/fashion & $0.36^{* * *}$ & $0.14^{* *}$ & -0.07 & $0.10^{*}$ & $0.09^{*}$ \\
\hline Recreational & $0.25^{* * *}$ & $0.21^{* * *}$ & 0.07 & 0.04 & 0.05 \\
\hline Price conscious & $-0.32^{* * *}$ & $-0.10^{*}$ & -0.01 & 0.06 & 0.01 \\
\hline Impulsiveness/Careless & $0.24^{* * *}$ & 0.06 & $-0.32^{* * *}$ & $0.19^{* * *}$ & -0.02 \\
\hline Confused & $-0.09^{*}$ & -0.03 & $-0.12^{* *}$ & $0.10^{*}$ & -0.09 \\
\hline Habitual/Brand- loyal & $0.11^{*}$ & -0.00 & 0.01 & -0.01 & $-0.10^{*}$ \\
\hline
\end{tabular}

\section{Personality and the meaning of branded products}

Further regression analysis was conducted to test the moderating effect of citizenship in the relation between the meaning of branded products and personality traits among Poland and the UK. The main reason to do that was to check if relationship between Polish and British citizens is different concerning the influence of personality on the way how consumers' perceive branded products (H7). The results suggested that citizenship is a moderator between the Traditions and Extraversion trait $(\mathrm{p}<0.001)$. Among Poles there is not significant relationship between these variables $(r=-0.08 ; p=0.27)$, whereas among the citizens in the UK this relation is positively significant $(\mathrm{r}=0.24 ; \mathrm{p}<0.001)$. 
Table 6

The result of Regression Analysis to Test Moderating Role of Citizenship for the Effect of Personality traits on the Meaning of Branded Products

\begin{tabular}{|c|c|c|c|c|}
\hline & beta & SE & $\mathrm{T}$ & $\mathbf{P}$ \\
\hline (Intercept) & -0.07 & 0.07 & -1.013 & 0.311 \\
\hline IPIP_E & -0.08 & 0.07 & -1.068 & 0.286 \\
\hline CitizenshipUK & 0.25 & 0.10 & 2.516 & 0.012 \\
\hline IPIP_E:CitizenshipUK & 0.34 & 0.10 & 3.451 & 0.001 \\
\hline
\end{tabular}

Further analysis also suggested that citizenship moderated the effect of Extraversion on the Family Traditions $(p<0.001)$. Among Poles there is not significant relationship between these variables $(\mathrm{r}=-0.08 ; \mathrm{p}=0.24)$, whereas among the UK this relationship is significant an positive $(\mathrm{r}=0.28 ; \mathrm{p}<0.001)$.

Table 7

The result of Regression Analysis to Test Moderating Role of Citizenship for the Effect of Personality traits on the Meaning of Branded Products

\begin{tabular}{|c|c|c|c|c|}
\hline & beta & SE & $\mathbf{T}$ & $\mathbf{P}$ \\
\hline (Intercept) & -0.12 & 0.07 & -1.644 & 0.101 \\
\hline IPIP_E & -0.09 & 0.07 & -1.188 & 0.236 \\
\hline CitizenshipUK & 0.35 & 0.10 & 3.499 & 0.001 \\
\hline IPIP_E:CitizenshipUK & 0.37 & 0.10 & 3.845 & $<0.001$ \\
\hline
\end{tabular}

Additionally, another regression analysis was conducted to test the moderating effect of age, gender, education and income on consumers' behaviour in both countries. It was done to check if these variables play a moderating role for the effect of personality traits on the way how consumers' perceive branded products (H8). Age appeared to have a moderating role on the relationship between Extraversion and Quality $(\mathrm{p}<0.01)$. Although, moderating effect of age on the relationship between this personality trait and a particular branded product meaning seemed to be significantly positive only among older individuals $(\mathrm{p}<0.01)$, whereas among younger consumers this relation was irrelevant.

Table 8

Regression Analyses to Test Moderating Role of Socio-demographic characteristics for the Effect of Personality traits on the Meaning of Branded Products

\begin{tabular}{|c|c|c|c|c|}
\hline & beta & SE & $\mathrm{t}$ & $p$ \\
\hline (Intercept) & 0.04 & 0.07 & 0.674 & 0.501 \\
\hline IPIP_E & 0.08 & 0.06 & 1.353 & 0.177 \\
\hline GenderMale & 0.22 & 0.12 & 1.887 & 0.060 \\
\hline Age & -0.05 & 0.06 & -0.867 & 0.386 \\
\hline Education & 0.02 & 0.06 & 0.404 & 0.687 \\
\hline Salary & 0.13 & 0.06 & 2.185 & 0.030 \\
\hline IPIP_E:Age & 0.16 & 0.06 & 2.910 & 0.004 \\
\hline
\end{tabular}


Table 9

The difference in a slope coefficient for Extraversion compared with middle age individuals in the regression model for the variables: Extraversion, Gender, Age, Education and Salary

\begin{tabular}{|c|c|c|c|c|}
\hline & simple slope & SE & $\mathrm{t}$ & p \\
\hline Low Age (-1 SD) & -0.067 & 0.074 & -0.91 & 0.365 \\
\hline High Age (+1 SD) & 0.244 & 0.081 & 3.02 & $0.003^{* *}$ \\
\hline
\end{tabular}

\section{Figure 1}

Moderating effect of age on the relationship between Extraversion and Brand Quality

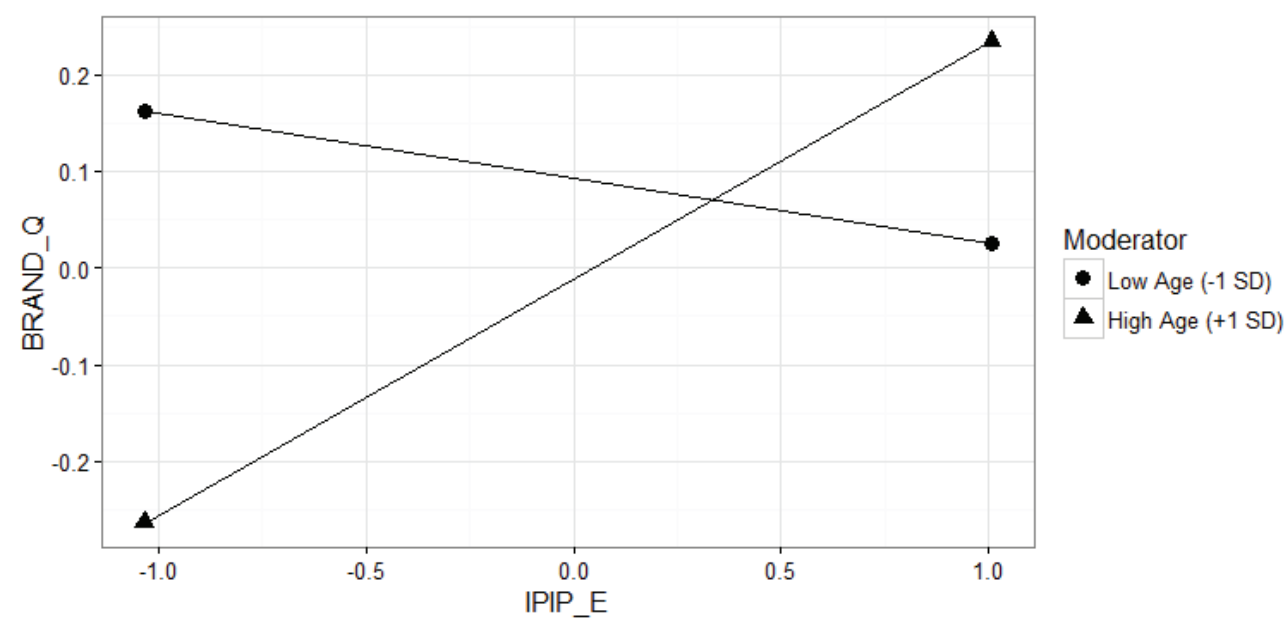

Table 10

The results of Regression Analysis between Extraversion and Age

\begin{tabular}{l|c|c|c|c} 
& Beta & SE & t & p \\
(Intercept) & 0.04 & 0.05 & 0.724 & 0.469 \\
IPIP_E & 0.12 & 0.05 & 2.532 & 0.012 \\
Age & 0.00 & 0.05 & -0.047 & 0.962 \\
IPIP_E:Age & 0.11 & 0.05 & 2.202 & 0.028
\end{tabular}

Another Pearson correlations were also computed to investigate the relationship between personality traits and the meaning of branded products (H9). Pearson correlations revealed a significant positive correlations between Extraversion and the Personal-identity $(r=0.24$; $p<0.001$, Table 11) and significantly positive correlation between the same personality trait and the Quality $(\mathrm{r}=0.13 ; \mathrm{p}<0.01$, Table 11$)$. Contrary to the prediction, there was no significant correlation between Extraversion and Values. $(r=0.07 ; p=0.12$, Table 11).

What is more, a significantly positive correlation between Conscientiousness and Traditions was also found ( $\mathrm{r}=0.09 ; \mathrm{p}<0.05$, Table 11). Moreover, contrary to the hypothesis, any evidence of a significant association between and Conscientiousness and Quality wasn't found $(\mathrm{r}=0.01$; $\mathrm{p}=0.91$, Table 11).

What is more, Pearson correlation revealed no significant association between Agreeableness and Traditions $(\mathrm{r}=-0.04 ; \mathrm{p}=0.402)$. Although a significant positive correlation between Agreeableness and Values was found $(\mathrm{r}=0.13 ; \mathrm{p}<0.01$, Table 11), which matched the prediction.

Additionally, a significant positive correlation between Imagination/Intellect and self-identity was found in the study $(r=0.13, \mathrm{p}<0.05$, Table 11) but there was no significant negative correlation between Neuroticism and Quality $(\mathrm{r}=0.01 ; \mathrm{p}=0.86$, Table 11). 
Table 11

Correlation between Personality traits and the Meaning of Branded Products scale

\begin{tabular}{|c|c|c|c|c|c|}
\hline & IPIP_E & IPIP_A & IPIP_C & IPIP_N & IPIP_I \\
\hline Quality & $0.13^{* *}$ & -0.00 & 0.01 & 0.01 & $-0.10^{*}$ \\
\hline Values & 0.07 & $0.13^{* *}$ & 0.05 & 0.08 & $0.11^{*}$ \\
\hline Self Identity & $0.24^{* * *}$ & $0.11^{*}$ & -0.01 & -0.04 & $0.13^{* *}$ \\
\hline Group Identity & $0.22^{* * *}$ & -0.02 & -0.08 & -0.02 & 0.01 \\
\hline Status & $0.17^{* * *}$ & -0.07 & -0.02 & 0.02 & -0.04 \\
\hline Family Traditions & 0.06 & -0.01 & $0.09^{*}$ & -0.06 & -0.05 \\
\hline National Traditions & 0.06 & -0.07 & 0.07 & -0.05 & -0.08 \\
\hline Personal Identity & $0.24^{* * *}$ & 0.01 & -0.04 & -0.02 & 0.04 \\
\hline Traditions & 0.07 & -0.04 & $0.09^{*}$ & -0.06 & -0.07 \\
\hline
\end{tabular}

${ }^{*} \mathrm{p}<0.05,{ }^{* *} \mathrm{p}<0.01,{ }^{* * *} \mathrm{p}<0.001$.

\section{DISCUSSION}

The current cross-cultural study aimed to investigate the influence of consumers' personality on shopping styles and how they perceived branded products. It is believed that this study may help to customize certain products and marketing campaigns taking into account people's personality and how it differs among countries. The present study revealed that The Big Five Personalities has an impact on consumers' shopping styles and the way how they perceive branded products, although, as a regression analysis showed, the moderating effect of citizenship seems to be significant only between Extraversion and Recreational and Shopping conscious style as well as Family Traditions and Traditions factors and only among British citizens.

The study reported that Neuroticism scored higher among Poles than the UK. It is not surprising since the previous investigations revealed that cultures with strong Uncertainty Avoidance usually achieve a higher score in that personality trait. (The Hofstede Centre, n.d) Poles express a very high preference for avoiding uncertainty. As it was mentioned, countries that exhibit high Uncertainty Avoidance tend to have rigorous codes of belief and disapprove of unconventional ideas. The UK, being, in contrary, a low Uncertainty Avoidance Index country, are comfortable in situations of ambiguity, their most recent decision to leave the European Union is a case in point. Surprisingly, since Great Britain scored higher on the Individualistic dimension than Poland (The Hofstede Centre, n.d), in the study Poland also scored higher on Extraversion which is typical for Individualistic countries. It can be explained by the recent study conducted by Urban and Cybal-Michalska (2016) which reported an obvious shift of beliefs and values among youth in Poland towards individualism. Young people appreciate the individualistic values, such as autonomy and perpetration and declare a strong need for self-realization.

Results of the study also suggesting a positive effect of Conscientiousness on Perfectionist, Careful-quality and Price-conscious shopping style and negative correlation with the Impulsiveness- Careless and Confused by Over-choice style. It can be explained by the fact that this kind of personality is naturally assiduous and careful. In contrast to the sensitivity of the extraversion client, this is a category of consumers who possess emotional stability. (McCrae and Costa, 1997). Hence, during shopping they carefully compare products in order to find the one that suits them best. Careful-quality conscious customers are systematic rather than impulsive and they are aware what exactly they require from the products. The present study also confirmed the theory about the sensitivity of the Extraversion consumers reviling that this personality 
trait is positively correlated to the Impulsiveness/Careless shopping style, Novelty/Fashion and Brand-conscious style and has a negative effect on the Price-conscious shopping habits. As it was mentioned, Extraversion means that the client is naturally outgoing and usually likes to impress others, so as Brand conscious consumers, who prefer bestselling and fashionable brands with higher prices. (Lynn, 2008) For them the more high-priced and well-known brands guarantee quality. Moreover, according to Fernandez (2009) Generation Y uses branded clothes as a way to tell the world that they belong to a particular group, or at least that they aspire to belong to it.

The results also suggesting positive effect of Imagination/Intellect on Novelty/Fashionconscious shopping and negative effect on Habitual Brand-loyal consumer style. It can be explained by the fact that this personality trait is associated with a deep interest in novelty, style, and new ideas. Imagination/Intellect is linked to extensive information searching and appetite for new sensations and experiences (Dowd \& McElroy, 2007). These consumers want to keep up to date with the latest trends, they seek variety and derive a sense of pleasure when they find a new style. (Chang et al., 2004)

The current study also revealed a significant positive correlation between Neuroticism and the Impulsiveness/Careless and Confused by Over-choice shopping style. The reason for that can be the fact that Neuroticism is a rather negative state, which is linked to emotional instability. It may lead to high level of stress and anxiety (Migliore, 2011) that can be the reason of Impulsiveness/ Careless shopping behaviour. It can be assumed that purchase decisions of this kind of consumers are the consequences of their actual emotional and psychological state.

The conducted study also reavealed a significant positive relationship between Agreeableness and the Recreational shopping style and negative effect on Price-conscious habits. It can be explained by the fact that agreeableness includes a category of buyers who is easier to do business with. They are not so self-centred and easily accept the opinions or suggestions of other people. Hence, they are more likely to buy certain products on guidance and persistence of seller or in adjustment to a spouse or friend (Whelan \& Davies, 2006).

As we can see, personality traits play a substantial role in consumers' purchase behaviour and the way how they shop, but this relations are not that straightforward. The analysis was extended to investigate a moderating role of citizenship, age, gender, income and education for the correlation between personality characteristics and consumers shopping styles. The results suggested that gender moderated the effect of Imagination/Intellect on the Habitual Brand-loyal conscious shopping style. Among females there is no significant Relationship between these variables whereas among males this relationship is significantly negative. It might be explained by the study conducted by Cross and Madson (1997) suggested that women and men create themselves variously. For instance, men have a tendency to be independent, which indicates that they mainly concentrate on their unique and distinctive attributes. On the other hand, females have a tendency to be interdependent, which implies that they are more socially-adapted and favour to grow up relationships and preserve closeness with other people.

Additionally, citizenship had moderated effect only of Extraversion on the Recreational and Shopping Conscious style. Although, among Poles there is no significant relationship between these variables, whereas around the UK this relation is significantly positive. The present study is the first one also investigating an influence of personality traits on the way how people perceive branded products and what leads them to buy certain things. The results suggesting that Extraversion has a positive effect on Self-identity. It can be explained by the fact that people with this personality try to express themselves by wearing a certain clothes which reflect their personality (Chang et al., 2004). It was found that they also value Quality, thus, the more expensive and well-known products are their choice. The results suggested that during purchasing they also follow their Values. It might be due to the fact that they are more confident than other consumers with different personality traits and they are also more sensitive to their environment, so they usually freely manifest their beliefs and morals. (McCrae and Costa, 1997) 
Quality has also been found to be positively correlated with Conscientiousness and negatively with Neuroticism, which is not surprising since consumers with this personality trait focus on their purchase products in order to find the best quality choice. Conscientiousness has also a positive effect on Traditions. It supported the prediction, since these consumers are careful, they are also much more likely take responsibility than other consumers. They believe in justice, and like to treat people fairly, in return, they expect fair treatment (McCrae and Costa, 1997). It might have an impact on their urge to care of certain morals and traditions. Like it was expected, Agreeableness has also a positive effect on Traditions. As it was mentioned above, these individuals easily accept the opinions or suggestions of other people, so they might be taught to cherish the tradition and pass it on further. (Whelan \& Davies, 2006). The results of the study also suggest that Imagination/ Intellect has a positive effect on Self-identity. It is not surprising since these consumers want to experiment and seek for variety. They are confident and not afraid of new experiences, concerning both, significant life-changes as well as new identity or appearance (Lynn, 2008).

This part was also extended to investigate moderating role of citizenship, age, gender, income and education for the relation between personality traits and consumers shopping styles. Age appeared to have a moderating role on the relationship between Extraversion and Quality. Although, moderating effect of age on the relationship between this personality trait and a particular branded product meaning seemed to be significantly positive only among older individuals, whereas among younger consumers this relation was irrelevant. This might be due to the fact that with age we are becoming more experienced and older individuals have a bigger knowledge about the shopping behaviour. They prefer to buy a better quality products which last longer than anything that just looks good and is fashionable at the moment. Additionally, citizenship had moderated effect only of Extraversion on the Traditions and Family Traditions. Although, among Poles there is no significant relationship between these variables, whereas around the UK this relation is significantly positive. In conclusion, we should bear in mind that consumer shopping styles have been studied across many different countries such as China (Tai, 2005), United Kingdom (Mitchell \& Bates, 1998) or Germany (Walsh et al., 2001), and each of them revealed different shopping styles depending on the culture. Distinctive nature of Polish consumer might have an impact on the shopping styles recognized in this analysis.

\subsection{Limitations and Future Research}

The authors of Consumer Styles Inventory (CSI) suggested that these dimensions can be different depending on the brand or product classification. The research did not specify a certain category and the context was general which could have some consequences for the results of the current study. (Sproles \& Kendall, 1986). Secondly, the respondents of the current study were recruited online via Prolificacademic.com and social networking sites and, since mainly young people use social media and earn money via online survey platforms, it might have influenced the sample. What is more, the data was collected over a 2-month period from July to September 2016. Collection of the data during the whole year could have produced different and more convincing results. We should also bear in mind that the way how we shop and behave in the market is not only a personality issue. Our decisions and shopping styles might also be influenced by many other personal or emotional factors and situations that we are currently in.

\section{CONCLUSION}

The current study aimed to investigate the influence of consumers' personality on their shopping styles and how they perceive branded products in the market. It focused mainly on crosscultural investigation between Poland and the UK. In order to investigate these relationships, 
extensive and broad literature concerning the buying behaviour was done and further analyses were carried out. The paper is divided into two main parts: in a theoretical one a relevant literature was briefly described and the previous findings were summarised and in the second part the results of the research was presented. The results show significant relationship between personality traits and both, consumer shopping styles and the way how individuals perceive branded products. Personality traits were assessed by the MINI-IPIP test (Donnellan et al., 2006), the 20-item instrument which measures the Big Five personalities. The buying behaviour was tested by two scales. The first one was a 39-item Consumer Shopping Inventory (Sproles \& Sproles, 1990), which indentifies eight shopping style dimensions. Another instrument was a 32-item the Meaning of Branded Products scale, (Strizhakova et al., 2008) presenting four dominant themes.

\section{PRACTICAL IMPLICATIONS}

Since individuals' behaviour derives partially from their personality, their behaviour as a consumer, which culminates in their purchasing decisions, can be traced back to the individual personality (Cleff et al., 2013). Hence, the marketing/brand managers need to gain this knowledge and find a way to adopt the personality theory in order to explore the consumers' behaviour and tailored their products and brands accordingly. Setting goals for the company's marketing require recognizing what the company actually wishes to be known for, and then spreading a coherent message across the world. Is the company sophisticated? eco-friendly? Innovative? or maybe with low prices? The character or personality of the company should reflect the desires and values of the target group of customers. One of the ingredients of the successful brand is to keeping it updated with the newest style, trend and fashion. What is more, concerning the market 'Perfectionists', the quality of the product should also be permanently controlled in order to maintain a good reputation of the brand. In addition, for Price-conscious consumers a price of the products needs to be reasonable and affordable. But obviously we cannot satisfy everyone so at first the company's profile need be established so a marketing campaign could be planned accordingly to the target customers.

\section{References}

Aaker, J.L. (1997). Dimensions of brand personality. Journal of Marketing Research, 34(3) 347-356.

Aaker, J., Fournier, S., \& Brasel, S.A. (2004). When good brands do bad. Journal of Consumer Research, 31(1), 1-16.

Bagozzi, R.P., \& Dholakia, U.M. (2006). Antecedents and purchase consequences of customer participation in small group brand communities. International Journal of Research in Marketing, 23(1), 45-61.

Barbaro, M. (2006, November 13). Candles, jeans, lipsticks: Products with ulterior motives. B33. The New York Times.

Beck, J.T., Chapman, K., \& Palmatier, R.W. (2015). Understanding Relationship Marketing and Loyalty Program Effectiveness in Global Markets. Journal of International Marketing, 23(3), 1-23.

Belk, R.W. (1988), Possessions and the extended self. Journal of Consumer Research, 15(2), 139-168.

Bellenger, D.N., \& Korgaonkar, P.K. (1980). Profiling the recreational shopper. Journal of Retailing, 56(3), 77-92.

Blackwell, R.D., Miniard, P.W., \& Engel, J.F. (2007). Consumer behavior (10th ed.). Kundi Haryana, India: Thomas South-Western.

Bloemer, J.M., \& Kasper, H.D. (1995). The complex relationship between consumer satisfaction and brand loyalty. Journal of Economic Psychology, 16(2), 311-329.

Boski, P. (2010). Kulturowe ramy zachowań społecznych, Podręcznik psychologii międzykulturowej, Warszawa: $P W N$.

Brakus J.J, Schmitt B.H., \& Zarantonello L. (2009). Brand Experience: What Is It? How Is It Measured? Does It Affect Loyalty?. Journal of Marketing, 73(3), 52-68.

Cabrera, A. (2006). Determinants of individual engagement in knowledge sharing. International Journal of Human Resource Management, 17(2), 245-264. 
Cankurt, M., Thomas, T., Gunden, C., \& Miran, B. (2013). Consumer decision-making styles: Investigation of food shopping behavior. Journal of Food, Agriculture \& Environment, 11(2), 224-227.

Melgoza, C. (2016). Multicultural Marketing Is All About the Metrics. Retrieved from https://www.entrepreneur. com/article/254347

Chang, E., Burns, L.D., \& Francis, S.K. (2004). Gender differences in the dimensional structure of apparel shopping satisfaction among Korean consumers: The role of hedonic shopping value. Clothing and Textiles Research Journal, 22(4), 185-199.

Cleff, T., Dörr, S., Vicknair, A., \& Walter, N. (2013). Brand Experience - How It Relates To Brand Personality, Consumer Satisfaction And Consumer Loyalty. An Empirical Analysis of The Adidas Brand. Interdisciplinary Management Research, 9, 732-755.

Clegg, A. (2005). A word to the worldly-wise. Marketing Week, 28(42), 44-49.

Crowe, E., \& Higgins, E. (1997). Regulatory focus and strategic inclinations: Promotion and prevention in decisionmaking. Organizational Behaviour and Human Decision Processes, 69(2), 113-133.

Costa, P.T., \& McCrae, R.R. (1980). Influence of extraversion and neuroticism on subjective well-being: Happy and unhappy people. Journal of Personality and Social Psychology, 38(4), 668-678.

Coulter, R.A., Price, L.L., \& Feick, L. (2003). Rethinking the origins of product involvement, involvement with branded products, and brand commitment: Women and cosmetics in postsocialist Central Europe. Journal of Consumer Research, 30 (Sept), 151-169.

Cross, S.E., \& Madson, L. (1997). Models of the self: Self-construals and gender. Psychological Bulletin, 122(1), 5-37. http://dx.doi.org/10.1037/0033-2909.122.1.5.

Culnan, M.J., McHugh, P.J., \& Zubillaga, J.I. (2010). How large U.S. companies can use twitter and other social media to gain business value. MIS Quarterly Executive, 9(4), 243-260.

Crossby, L.A., \& Grossbart, S.L. (1984). A blue print for consumer research on personality. Advances in Consumer Research, 11, 447-452.

Dąbrowska, J. (2008). Cross-cultural marketing - the impact of Polish culture on marketing in Poland. White Paper. ClusterStar, 1-11.

De Mooij, M. (2004). Consumer behavior and culture: Consequences for global marketing and advertising. Thousand Oaks: Sage Publications, Inc.

Deshpande, R., Hoyer, W.D., \& Donthu, N. (1986). The intensity of ethnic affiliation: A study of the sociology of Hispanic consumption. Journal of Consumer Research, 13(2), 214-220.

Wang, D. (2016). Why Home-Grown Brands Will save The Chinese Dream. Retrieved from www.forbes.com/sites/ onmarketing/2016/06/24/why-home-grown-brands-will-save-the-chinese-dream/\#4b925df81305

Donnellan, M.B., Oswald, F.L., Baird, B.M., \& Lucas, R.E. (2006). The Mini-IPIP scales: Tiny-yet-effective measures of the Big Five factors of personality. Psychological Assessment, 18(2), 192-203.

Douglas, S. P., \& Craig, C. S. (2006). On improving the conceptual foundations of international marketing. Journal of International Marketing, 14(1), 2-21.

Dowd, K., \& McElroy, T. (2007). Susceptibility to anchoring effects: How openness-to experience influences responses to anchoring cues. Journal of Judgment and Decision Making, 2(1), 48-53.

Escalas, J., \& Bettman, J. (2003). You are what they eat: The influence of reference groups on consumers' connections to brands. Journal of Consumer Psychology, 13(3), 339-348.

Eurostat. (2002). How Europeans spend their time. Brussels: European Commission.

Feick, L.F., Coulter, R.H., \& Price, L.L. (1995). Consumers in the transition to a market economy: Hungary, 19891992. International Marketing Review, 12(5), 18-34.

Fernandez, P.R. (2009). Impact of branding on Gen Y's choice of clothing. The Journal of the South East Asia Research Center, 1(1), 79-95.

Fiore, A.M \& Damhorst, M.L. (1992). Intrinsic cues as predictors of perceived quality of apparel. Journal of Consumer Satisfaction, Dissatisfaction and Complaining Behavior, 5, 168-177

Fournier, S. (1998). Consumers and their brands: Developing relationship theory in consumer research. Journal of Consumer Research, 24(4), 343-373.

Gam, H.J. (2011). Are fashion-conscious consumers more likely to adopt eco-friendly clothing?. Journal of Fashion Marketing and Management, 15(2), 178-193.

Gąsiorowska, A. (2011). Gender as a moderator of temperamental causes of impulse buying tendency. Journal of Customer Behaviour, 10(2), 119-142.

The Hofstede Centre (2017) Country comparison - Poland. Retrieved from https://geert-hofstede.com/poland.html

Gehrt, K.C., \& Carter, K.(1992). An exploratory assessment of catalog shopping orientations: Existence of convenience and recreational segments. Journal of Direct Marketing, 6(1), 29-39.

Gelb, B., \& Sorescu, A.B. (2000). Republican brands, democrat brands. Journal of Advertising Research, 40(1), 95-102.

Gobé, M. (2001). Emotional branding: The new paradigm for connecting brands to people. New York: Allworth Press. 
Guthrie, M.F., \& Kim, H.S. (2008). The relationship between consumer involvement and brand perceptions of female cosmetic consumers. Journal of Brand Management, 17(2), 114-133.

Hawkins, D. ., Best, R.J., \& Coney, K.A. (1989). Consumer behaviour (4 ${ }^{\text {th }}$ edition). Boston: BPI Irwin.

Hawkins, D.I., Best, R.J., \& Coney, K.A. (1995). Consumer behaviour: Implications for marketing (6th ed.). Chicago, IL: Richard D. Irwin.

Hellofs, L.L., \& Jacobson, R. (1999). Market share and customers' perceptions of quality: When can firms grow their way to higher versus lower quality? Journal of Marketing, 63(1), 16-25.

Hirschman, E.C., \& Holbrook, M.B. (1982). Hedonic consumption: emerging concepts, methods and propositions. Journal of Marketing, 46(3), 92-101.

Hofstede G., Hofstede G.J. (2007), Kultury i organizacje, Warszawa: PWE.

Hofstede, G. (2011). Dimensionalizing Cultures: The Hofstede Model in Context. Online Readings in Psychology and Culture, 2(1). Retrieved from http://dx.doi.org/10.9707/2307-0919.1014

Hofstede, G., De Mooij, M. (2011) Cross-Cultural Consumer Behaviour: A Review of Research Findings, Journal of International Consumer Marketing, 23(3-4), 181-192.

Holt, D.B., Quelch, J.A., \& Taylor, E.L. (2004). How global brands compete. Harvard Business Review, 82(9), 68-75.

Jacoby, J., \& Chestnut, R.W. (1978). Brand Loyalty: Measurement and Management. New York: John Wiley and Sons.

Stachura, J., \& Murphy, M. (2005). Multicultural marketing: why one size does not fit all. Retrieved from http:// www.thewisemarketer.com/features/read.asp?id=80

Kamaruddin, A., \& Mokhlis, S. (2003). Consumer Socialization, social structural factors and decision-making styles: a case study of adolescents in Malaysia. International Journal of Consumer Studies, 27(2),146-156.

Kaynak, E., \& Kara, A. (1998). Consumer ethnocentrism and lifestyle orientation in an emerging market economy. Management International Review, 38, 53-73.

Keller, K.L. (2003). Strategic brand management, Upper Saddle River: Prentice Hall.

Kjeldgaard, D., \& Askegaard, S. (2006). The globalization of youth culture: The global youth segment as structures of common differences. Journal of Consumer Research, 33(2), 231-247.

Kleine, R.E., III, Schultz-Kleine, S., \& Kernan, J.B. (1992). In J.F. Sherry Jr. \& B. Sternthal (Eds.), Mundane everyday consumption and the self: A conceptual orientation and prospects for consumer research. Advances in Consumer Research, 19, 411-415.

Korgaonkar, P.K., Lund, D., \& Price, B.(1985). A structural equations approach toward examination of store patron age behavior. Journal of Retailing, 61, 39-60.

Kozhevnikov, M. (2007). Cognitive styles in the context of modern psychology: toward an integrated framework of cognitive style. Psychological Bulletin, 133 (3), 464-481.

Lastovicka, J.L. (1982). On the validation of lifestyle traits: a review and illustration. Journal of Marketing Research, 19(1),126-138.

Lauriola, M., \& Levin, I.P. (2001). Personality traits and risky decision-making in a controlled experimental task: An exploratory study. Personality and Individual Differences, 31(2), 215-226.

Leo, C., Bennett, R., \& Härtel, C.E.J. (2005). Cross-cultural differences in consumer decision-making styles. CrossCultural Management: An International Journal, 12 (3), 32-62.

Levy, S.J. (1959). Symbols for sale. Harvard Business Review, 37(4), 117-124.

Lynn, M. (2008). Personality effects on tipping attitudes, self-reported behaviors and customs: A multi-level inquiry. Retrieved from http://scholarship.sha.cornell.edu/ articles/26

Martins, N. (2002). A model for managing trust. International Journal of Manpower, 23 (8), 754-769.

Maynes, E.S. (1976). Decision-Making for Consumers: An Introduction to Consumer Economics. New York: Macmillan, New York.

McCrae, R. \& Costa, P.T. (1997). Personality trait structure as a human universal. American Psychologist, 52(5), 509-516.

McCrae, R.R., \& John, O.P. (1992). An introduction to the five-factor model and its applications. Journal of Personality, 60(2), 172-215.

McCrae, R.R. \& Costa, P.T. (1990). Personality in Adulthood. New York: Guildford Press,.

Migliore, L.A. (2011). Relation between Big Five personality traits and Hofstede's cultural dimensions: samples from the USA and India. Cross Cultural Management: An International Journal, 18(1), 38-54.

Fromowitz, M. (2013). Cultural blunders: Brands gone wrong. Retrieved from http://www.campaignasia.com/article/ cultural-blunders-brands-gone-wrong/426043

Mitchell, V. \& Bates, L. (1998). UK consumer decision-making styles. Journal of Marketing Management, 14(1-3), $198-224$

Moschis, G.P. (1976). Social comparison and informal group influence Journal of Marketing Research, 13(3), 237-244. 
Mulyanegara, R.C., Tsarenko, Y., \& Anderson, A. (2009). The Big Five and brand personality: Investigating the impact of consumer personality on preferences toward particular brand personality. Journal of Brand Management, 16(4), 234-247.

Muniz, A M., \& O’Guinn, T. C. (2001). Brand community. Journal of Consumer Research, 27(4), 412-432.

Penaloza, L. (1994). Atravesando fronteras/ border crossings: A critical ethnographic study of consumer acculturation of Mexican immigrants. Journal of Consumer Research, 21(1), 32-53.

Phillips, T. (2007). Knockoff: The Deadly Trade in Counterfeit Goods: the True Story of the World's Fastest Growing Crime Wave. London: Kogan Page.

Ram, H.S.G., Ravindran, D.S., \& Vivek, M.S. (2009). Study on Shopping Orientation and Consumption of Fashion Among Youth. ACUMEN, 83-97

Riding, R., \& Cheema, I. (1991). Cognitive styles - an overview and integration. Educational Phychology, 11(3), 193-215.

Saraneva, A., \& Sääksjärvi, M. (2008). Young compulsive buyers and the emotional roller-coaster in shopping. Young Consumers: Insight and Ideas for Responsible Marketers, 9(2), 75-89.

Scherhorn, G., Reisch, L.A., \& Raab, G. (1990). Addictive buying in West Germany: An empirical study. Journal of Consumer Policy, 13(4), 355-355.

Schmitt, B.H. (1999). Experiential marketing: How to get customers to sense, feel, think, act, relate. New York: The Free Press.

Siu, N.M., Wang, C.C.L., \& Chang, L.M.K. (2001). Adapting consumer style inventory to Chinese consumers: a confirmatory factor analysis approach. Journal of International Consumer Marketing, 13(2), 29-47.

Sproles, E.K. and Sproles, G.B. (1990). Consumer decision-making styles as a function of individual learning styles. The Journal of Consumer Affairs, 24 (1),134-47.

Sproles, G. B. (1985). From perfectionism to faddism: measuring consumers' decision-making styles. In: Proceedings American Council on Consumer Interests, USA, 79-85.

Sproles, G.B., \& Kendall, E.L.(1986). A methodology for profiling consumers' decision-making styles. Journal of Consumer Affairs, 20(2), 267-279.

Stephenson, R.P., \& Willett, R.P.(1969). Analysis of consumers' retail patron age strategies. In: McDonald, P.R.(Ed.), Marketing Involvement in Society and the Economy. American Marketing Association, Chicago, 316-322.

Stone, G.P. (1954). City shoppers and urban identification: observations on the social psychology of city life. American Journal of Sociology, 60(1),36-45.

Strizhakova, Y., Coulter, R.A., \& Price, L.L. (2008). The meaning of branded product: A cross-national scale development and meaning assessment. International Journal of Research in Marketing, 25(2), 81-94

Supphellen, M., \& Gronhaug, K. (2003). Building foreign brand personalities in Russia: The moderating effect of consumer ethnocentrism. International Journal of Advertising, 22(2), 203-226.

Tai, S.H. (2005). Shopping styles of working Chinese females. Journal of Retailing and Consumer Services, 12(3), 191-203.

Taylor, C. R., \& S. Okazaki. (2006). Who standardizes advertising more frequently, and why do they do so? A comparison of U.S. and Japanese subsidiaries' advertising practices in the European Union. Journal of International Marketing, 14(1), 98-120.

Thompson, F.M., \& Chmura, T. (2015). Loyalty Programs in Emerging and Developed Markets: The Impact of Cultural Values on Loyalty Program Choice. Journal of International Marketing, 23(3), 87-103.

Tsai, S.-P. (2005). Utility, cultural symbolism and emotion: A comprehensive model of brand purchase value. International Journal of Research in Marketing, 22(3), 277-291.

Tsao, W., \& Chang, H. (2010). Exploring the impact of personality traits on online shopping behavior. African Journal of Business Management, 4(9), 1801-1813.

Walsh, G., Mitchell, V.W., \& Hennig Thurau, T. (2001). German Consumer Decision Making Styles. Journal of Consumer Affairs, 35(1), 73-95.

Wang, C.C., \& Yang, Y.J. (2007). Personality and intention to share knowledge: An empirical study of scientists in an R\&D Laboratory. Journal of Social Behavior and Personality, 35(10), 1427-1436.

Wells, W.D. (1974). Life Style and Psychographics. Chicago: American Marketing Association,

Westbrook, R.A., \& Black, W.C. (1985). A motivation - based shopper typology. Journal of Retailing, 61(1),78-103.

Whelan, S., \& Davies, G. (2006). Profiling consumers of own brands and national brands using human personality. Journal of Retailing and Consumer Services, 13(6), 393-402.

Williams, R.H., Painter, J.J., \& Nicholas, H.R. (1978). A policy-oriented typology of grocery shoppers. Journal of Retailing, 54(1), 27-43.

Zhang Y., \& Wang F. (2010) The Relationship Between Impulse Buying, Negative Evaluations and Customer Loyalty, Orient Academic Forum, 131-139. 